\title{
A PESQUISA EDUCACIONAL COMO ATIVIDADE CURRICULAR NA FORMAÇÃO DE LICENCIANDOS DE QUÍMICA
}

\section{The Educational Research as a curricular activity in the Education of Undergraduates in Chemistry}

\author{
Fábio André Sangiogo ${ }^{1}$ \\ Raquel Woyciechoswsky ${ }^{2}$ \\ Simone Albrecht da Rosa ${ }^{3}$ \\ Otavio Aloísio Maldaner ${ }^{4}$
}

Resumo: O artigo reflete sobre a atividade de pesquisa educacional desenvolvida no componente curricular Pesquisa em Ensino de Química II, um dos componentes de iniciação à pesquisa educacional no curso de Química-Licenciatura da UNIJUÍ. Licenciandos, por meio de questionário respondido por acadêmicos de Química e da terceira série do Ensino Médio, identificaram diferentes níveis de significação envolvendo conceitos científicos fundamentais na compreensão das transformações químicas e seus efeitos térmicos. As respostas foram agrupadas segundo sua semelhança, resultando na construção de quatro categorias de análise para ambos os grupos. Foram consultados, também, livros didáticos de química do Ensino Médio e do Ensino Superior, que abordam o tema investigado. Com base no relato da pesquisa desenvolvida por licenciandos, conclui-se que a iniciação à pesquisa educacional pode ser realizada como atividade curricular, de modo a potencializar a formação do professor também como pesquisador de sua prática.

Palavras-chave: Pesquisa em educação. Ensino de Química. Formação de professores. Ensino Superior. UNIJUÍ.

\begin{abstract}
The article reflects about the educational research activity developed at the curriculum component - Research in the Teaching of Chemistry II -, one of the components of introduction to the educational research in the course of Chemistry at UNIJUÍ. Undergraduates, through a questionnaire answered by students of Chemistry and by students from the third year of high school, identified different levels of meaning involving fundamental scientific concepts in the understanding of chemical transformations and their thermal effects. The responses were grouped according to their similarity, resulting in the construction of four categories of analysis for both groups, were also consulted books of chemistry for high school and university teaching that address the investigated subject. Based on the report of research developed by undergraduates, it is concluded that the initiation to the educational research can be performed as a curricular activity in order to enhance the education of the teacher also as researcher of his practice.
\end{abstract}

Keywords: Research in education. Chemistry education. Teaching. Higher education. UNIJUÍ.

\footnotetext{
${ }^{1}$ Graduado em Química, mestre em Educação nas Ciências, doutorando em Educação Científica e Tecnológica, Universidade Federal de Santa Catarina. Florianópolis, SC, Brasil. < fabiosangiogo@gmail.com>

${ }^{2}$ Graduada em Química. Secretária em Clínica Médica. Santo Augusto, RS, Brasil. < raquelwoy@hotmail.com>

${ }^{3}$ Graduada em Química. Agente Educacional II - Administração Escolar. Escola Técnica Estadual 25 de Julho. Ijuí, RS, Brasil.<simonealbrecht@bol.com.br>

${ }^{4}$ Graduado em Filosofia e Ciências Naturais - Habilitação em Química, mestre em Química Inorgânica e doutor em Educação. Docente, Programa de Pós-Graduação em Educação nas Ciências, Universidade Regional do Noroeste do Estado do Rio Grande do Sul. Ijuí, RS, Brasil. <maldaner@unijui.edu.br>

${ }^{1}$ Programa de Pós-Graduação em Educação Científica e Tecnológica

UFSC - Centro de Ciências Físicas e Matemáticas

Campus Trindade

Florianópolis, SC

523

$88.040-900$

Ciência छ̊̊ Educação, v. 17, n. 3, p. 523-540, 2011
} 


\section{Introdução}

A pesquisa educacional, como princípio e prática de formação nas licenciaturas, vem sendo proposta há mais de uma década no Brasil e em outros países. Dentro dos programas de Iniciação Científica (IC), essa prática é reconhecida como sendo de grande eficácia no desenvolvimento intelectual dos acadêmicos, proporcionando maior autonomia no exercício profissional e na formação continuada. A IC, no entanto, costuma abranger um pequeno número de licenciandos. Por isso, cresce o número de experiências em que a iniciação à pesquisa é proposta como atividade curricular, buscando abranger a totalidade dos licenciandos de um curso. O presente artigo traz resultados e discussões sobre uma dessas experiências realizada na Licenciatura de Química da Universidade Regional do Noroeste do Estado do Rio Grande do Sul (Unijuî). Em componentes curriculares que são propostos no decorrer de cinco semestres do Curso, a pesquisa educacional é ensinada e praticada como atividade curricular há quase uma década. Mais que analisar os resultados produzidos pelos licenciandos, por exemplo, sob o ponto de vista da correção conceitual em Química, a preocupação do artigo é a de mostrar o nível de desenvolvimento da pesquisa educacional como atividade curricular coletivamente orientada. Até aqui, conhecem-se poucos resultados dessa atividade fora dos programas de IC.

O trabalho de pesquisa foi proposto e realizado no componente Pesquisa em Ensino de Química II (PEQ II), que é inserido na grade curricular como quinto componente, com a finalidade de propiciar o desenvolvimento da pesquisa educacional como atividade curricular na graduação.

Em PEQ II, os acadêmicos propõem e executam projeto de pesquisa ligado ao contexto escolar no que se refere ao processo de ensino e aprendizagem em química. Para isso, fazem contato com escolas, interagem com estudantes e professores do Ensino Médio, entram em contato com produções científicas mais recentes sobre educação química. Na execução de seus projetos, os acadêmicos são orientados a seguirem os passos do "ritual" de uma pesquisa, entre os quais: concepção e elaboração do projeto; submissão de aprovação do projeto pelo professor do componente curricular; negociação do espaço para a produção de dados de pesquisa junto às escolas; negociação de acordo com os sujeitos da pesquisa na escola; construção, análise e discussão dos dados da pesquisa; comunicação e/ou publicação dos resultados em algum evento interno da instituição ou em outros eventos locais e/ou nacionais.

A pesquisa desenvolvida por um dos grupos de licenciandos, que é referida e apresentada parcialmente neste artigo, destinou-se a identificar a compreensão química que acadêmicos e estudantes de Ensino Médio têm sobre fenômenos do cotidiano que envolvem transformações na matéria e fenômenos energéticos. Com base em Lopes (1997), compreende-se que a interpretação de fenômenos, como aqueles que envolvem transformações químicas, decorre de processos de significação de conhecimentos escolares, oriundos de inter-relações dinâmicas entre conhecimentos cotidianos e científicos/químicos. Os conhecimentos que permitem entender o cotidiano estão se tornando mais complexos num mundo que se estrutura cada vez mais na tecnologia de base científica. Entende-se que é importante se compreenderem essas interrelações para se propiciarem, aos estudantes, capacidades como aquelas propostas nas Orientações Curriculares Nacionais: "que, ao acessar a informação, o aluno tenha condições de decodificá-la, interpretá-la e, a partir daí, emitir um julgamento" (BRASIL, 2006, p. 33). O ensino, com a preocupação de produzir sentido aos conhecimentos necessários no agir cotidi- 
A pesquisa educacional como atividade curricular ...

ano, proporciona melhores condições ao estudante de "participar ativamente dos problemas relacionados à comunidade em que está inserido" (SANTOS; SCHNETZLER, 1997, p. 94), desenvolvendo capacidades para "a tomada de decisão, [...] emitindo a sua opinião, a partir de um sistema de valores e das informações fornecidas, dentro de um comprometimento social" (SANTOS; SCHNETZLER, 1997, p. 94, grifo dos autores).

Ao desenvolver a pesquisa educacional em sua formação na graduação, o licenciando terá a oportunidade da aprendizagem de importantes ferramentas culturais produzidas no âmbito da comunidade científica. Isso possibilita a construção de visões que se estendem para a dinamicidade que envolve os processos de construção de conhecimentos escolares, diferente da concepção tradicional de ensino baseada, meramente, na ideia de transmissão-recepção de conhecimentos. Ao constituir-se como pesquisador na formação inicial, como professor estará preparado para

[...] refletir a respeito de sua prática de forma crítica, de ver a sua realidade de sala de aula para além do conhecimento na ação e de responder, reflexivamente, aos problemas do dia-a-dia nas aulas. É o professor que explica as suas teorias tácitas, reflete sobre elas e permite que os alunos expressem o seu próprio pensamento e estabeleçam um diálogo reflexivo recíproco que, dessa forma, o conhecimento e a cultura possam ser criados e recriados juntos a cada indivíduo. (MALDANER, 2003, p. 30)

A formação proposta no curso de Química-Licenciatura explicita, de forma clara, em seu Projeto Pedagógico, a constituição do professor pesquisador. Tal formação pode permitir, aos profissionais de ensino, nova visão do processo de ensino e aprendizagem em química, visão que, infelizmente, é fortemente baseada na concepção própria da racionalidade técnica em praticamente todos os cursos universitários (SCHÖN, 1983). Percebe-se, no Projeto Pedagógico do Curso, a tentativa de se superar essa racionalidade, e constata-se maior preocupação para que a construção do conhecimento químico escolar seja buscada na inter-relação dialógica de conhecimentos cotidianos e científicos. Esses conhecimentos, por serem de natureza diversificada, complementam-se e requerem-se mutuamente em movimentos de reciprocidade nos contextos escolares.

A defesa da dialogia entre conhecimentos cotidianos e científicos não minora a compreensão de que a química é uma ciência que envolve o uso de conhecimentos específicos, com simbologias criadas para permitir a compreensão da matéria e sua transformação em nível atômico-molecular; fortalece a oportunidade da melhor apropriação da linguagem, da significação conceitual pelo uso de muitos signos em contexto que, segundo Vigotski (2001), precisam ser internalizados durante a vivência escolar. O processo interativo, fortalecido na dialogia, possibilita a constituição do sistema simbólico para um novo pensar sobre o mundo.

Apesar da compreensão de que a sala de aula represente o espaço em que o conhecimento mais poderoso - o conhecimento próprio das ciências (YOUNG, 2007) - seja apropriado pelos estudantes, defende-se a necessidade de sua recontextualização no âmbito da escola. Isso demanda a necessidade de, em alguns momentos, se propiciarem rupturas com visões do senso comum que emergem da vivência cotidiana dos estudantes (BACHELARD, 1996), bem 
como se propiciar a recontextualização dos conhecimentos científicos que permeiam o discurso ou narrativa, em sala de aula, dos professores e/ou livros didáticos. Tudo isso, de modo a possibilitar que os estudantes possam melhor entender situações vivenciais, como é o caso das transformações químicas que envolvem efeitos energéticos (a exemplo da combustão). Afinal, "a ciência, em geral, depois de ter rompido com o senso comum, deve transformar-se num novo e mais esclarecido senso comum" (SOUZA SANTOS, 2003, p. 9).

Defende-se a necessidade de se articularem os "saberes e conteúdos das ciências entre si e, também, com os saberes cotidianos trazidos das vivências dos alunos de fora da escola, permitindo uma abordagem com característica interdisciplinar, intercomplementar e transdisciplinar" (MALDANER; ZANON, 2001, p. 1), essencial para o exercício responsável da cidadania, como interpretar e tomar as melhores decisões sobre as situações complexas que permeiam a vida cotidiana das pessoas. No entanto, a apropriação desses saberes demanda que os professores superem a compreensão do ensino em sua forma apenas disciplinar e compreendam as relações complexas e multidimensionais que permeiam as situações da vida cotidiana. Para Morin (2006), isso envolve uma teia de sentidos e significações em que as partes ensinadas no âmbito de uma disciplina podem permitir entendimentos do todo em contexto transdisciplinar.

Com base em Galiazzi (2003, p. 159), entende-se ser preciso perceber a aprendizagem como processo de construção gradativa do conhecimento, processo esse sempre inacabado, "cíclico, incompleto, dinâmico, em que aprendem juntos, professores e alunos". Afinal, os estudantes não irão se apropriar de conhecimentos de forma mecânica e sair usando-os no dia a dia, mas sim criar laços que permitem relacioná-los à sua vivência através da mediação inicial do outro (pais, professores e colegas), que também aprende (VIGOTSKI, 2001). No entanto, ainda prevalece a ideia de que professores e estudantes entendem "que tudo vai ser aprendido de uma só vez, desde que o professor mostre o conteúdo" (GALIAZZI, 2003, p. 197). Entendimento este decorrente do ensino tradicional baseado na transmissão-recepção de conhecimentos, a partir do qual se tem a falsa compreensão de que o estudante sabe ciências/química quando consegue repetir o conceito que é repassado pelo professor em aula; concepção que necessita de enfrentamentos e discussões junto à formação docente, em que as atividades de pesquisa educacional conduzidas no contexto escolar ou universitário podem ser um dos momentos para isso.

O ensino praticado na maioria das escolas com base em livros didáticos tradicionais não consegue significar as muitas dimensões do conhecimento para torná-lo poderoso no contexto da vida das pessoas. $\mathrm{Na}$ forma com que se apresenta o conhecimento na maioria dos livros didáticos de Química utilizados nas escolas, simplifica-se demasiadamente, por exemplo, a complexa questão das transformações químicas e seus efeitos energéticos. Os estudantes acabam apresentando significados conceituais limitados, sobretudo no que se refere às explicações em nível atômico-molecular das transformações químicas e à origem dos efeitos energéticos associados. Resultados de pesquisa educacional envolvendo aspectos relacionados ao ensino e aprendizagem sobre as transformações químicas, por parte de estudantes, já foram apresentados em outras pesquisas, como em Rosa e Schnetzler (1998), Souza (2007) e Barros (2009), que confirmam esses problemas de compreensão submicroscópica das transformações na matéria. 
A pesquisa educacional como atividade curricular ...

Neste artigo, discutem-se resultados produzidos em pesquisa desenvolvida sobre conhecimentos escolares de química, embora o objetivo principal seja o de mostrar que ela pode ser desenvolvida como atividade curricular, envolvendo todos os estudantes de uma turma. Isso é diferente da IC tradicional, em que há relação muito próxima entre um orientador e um estudante ou pequeno grupo de estudantes. $\mathrm{Na}$ IC, a atividade de pesquisa realizada, em geral, não contabiliza horas para a integralização da carga horária do curso. Defende-se, enfim, com base na pesquisa produzida por licenciandos, que o processo formativo pela/ e na pesquisa educacional é possível, e produz desenvolvimento intelectual compatível para que os licenciandos possam ser considerados iniciados na pesquisa educacional, mesmo que não tenham participado de programas de IC.

\section{Aspectos metodológicos}

Tendo em vista que o objetivo maior é refletir sobre a pesquisa educacional desenvolvida como atividade curricular na formação docente, apresentam-se, inicialmente, os procedimentos metodológicos que orientaram a execução da pesquisa em PEQ II, mais especificamente, a metodologia desenvolvida e realizada por um dos grupos de licenciandos que visava encontrar respostas às questões: qual o nível real de significação de conceitos fundamentais para se pensarem as transformações químicas e seus efeitos energéticos? Como esses conceitos são apresentados em livros didáticos de química? Como os estudantes do curso da licenciatura de Química e do Ensino Médio interpretam situações reais que envolvem o uso desses conceitos? Reitera-se que, para além de apresentar resultados de pesquisa sobre tais questões, o artigo reflete sobre as ações e avanços produzidos pelo grupo, apresentando partes do trabalho publicado e apresentado no XIV Encontro Nacional de Ensino de Química (XIV ENEQ), por um dos grupos de licenciandos (SANGIOGO et al., 2008).

A pesquisa desenvolvida pelo grupo de licenciandos é de natureza qualitativa. As respostas dos estudantes, sujeitos da pesquisa, às questões propostas foram consideradas como documentos a serem analisados, cientes de que

Ao considerar os diferentes pontos de vista dos participantes, os estudos qualitativos permitem iluminar o dinamismo interno das situações, geralmente inacessíveis ao observador externo [...]. Deve, por isso, encontrar meios de checá-las, discutindo-as abertamente com os participantes ou confrontando-as com outros pesquisadores para que elas possam ser ou não confirmadas. (LÜDKE; ANDRÉ, 1986, p. 12-13)

No componente PEQ II, foi proposto como tema de pesquisa: verificar, a partir de um questionário com quatro questões abertas e ligadas a situações de vivência dos estudantes, o nível de significação de conceitos químicos básicos no entendimento das situações apresentadas. As situações foram apresentadas na forma de questões, que foram respondidas por escrito por estudantes do curso de Química-Licenciatura e do $3^{\circ}$ ano do Ensino Médio. O entendimento das situações envolvia conteúdos relativos: (I) a transformações químicas e 
efeitos energéticos, (II) à neutralização ácido/base em meio aquoso, (III) a modelos de representação em nível atômico-molecular de fenômenos químicos, e (IV) a ligações químicas, de modo que os estudantes pudessem utilizar conhecimentos químicos já estudados em diferentes momentos do período escolar/universitário. Cada situação foi analisada por um grupo de licenciandos que cursavam PEQ II, ambos sob a orientação do professor do componente curricular.

Neste artigo são apresentados resultados sobre a situação "I", que envolvia entendimentos sob o ponto de vista das transformações químicas e os seus efeitos energéticos. A pesquisa desenvolvida pelos licenciandos compreendeu três fases. Em todas houve debate em grupo, para que as primeiras percepções fossem explicitadas e se tomasse maior consciência delas por meio do aprofundamento teórico que se deu no decorrer de ambas as fases.

$\mathrm{Na}$ fase I, os acadêmicos responderam ao questionário proposto pelo professor do componente curricular PEQ II, envolvendo os conteúdos apresentados anteriormente. Quarenta e cinco acadêmicos (do $3^{\circ}$ ao $8^{\circ}$ semestre) do curso de Química-Licenciatura responderam ao questionário. Cada grupo de estudantes de PEQ II desenvolveu uma pesquisa, com produção e análise de dados a partir das respostas produzidas pelos acadêmicos. Segue a questão analisada neste trabalho e que se refere à pergunta analisada por um dos grupos de licenciandos:

"Muitas transformações químicas são acompanhadas por efeitos energéticos, como as combustões, por exemplo. De onde vem a energia liberada nesses tipos de reações quimicas?" (Questão respondida pelos licenciandos, referente às transformações químicas e efeitos energéticos).

As respostas dos acadêmicos foram codificadas com um número, que corresponde ao acadêmico $(1,2,3 \ldots)$, e outro número, em algarismos romanos, que permite saber a qual turma pertencia o estudante (I, II e III), tendo em vista que as mesmas questões foram respondidas por três turmas diferentes do Curso.

$\mathrm{Na}$ fase II, procedeu-se à leitura e análise de livros didáticos de Química de Ensino Médio e Ensino Superior e à leitura de referenciais teóricos de cunho pedagógico e epistemológico sobre o tema investigado. As leituras destinavam-se a ajudar a construir o referencial teórico, a entender e a aprofundar conhecimentos que permitiriam melhor organização e análise das respostas produzidas pelos acadêmicos, relacionando ensino e aprendizagem, conteúdos/conceitos de química sobre o tema investigado. Realizou-se uma análise de livros didáticos (citados nas referências), mencionados, neste texto, na forma de códigos, com o propósito de se evitarem julgamentos de valores sobre editoras e autores. Os livros didáticos do Ensino Médio são referidos como LD1, LD2 etc., e os do Ensino Superior como LDS1, LDS2 etc. Os livros citados nas referências foram escolhidos pelo fato de o grupo de licenciandos ter acesso fácil aos mesmos.

$\mathrm{Na}$ fase III, tendo em vista os resultados obtidos junto aos licenciandos, houve a elaboração de novo questionário, mais adequado para o nível médio. A questão inicial sobre as transformações químicas, respondida pelos licenciandos, foi desdobrada em três, para serem respondidas por estudantes do $3^{\circ}$ ano do Ensino Médio de uma escola pública. A questão foi reelaborada com o objetivo de permitir que eles pudessem expressar, com mais precisão, seus conhecimentos e entendimentos sobre a origem dos efeitos energéticos em transformações químicas exotérmicas, nas quais se reconhecem e evidenciam efeitos energéticos. 
A pesquisa educacional como atividade curricular ...

Na termoquímica você usa os conceitos de transformação química exotérmica $(\Delta H<0)$ e endotérmica $(\Delta H>0)$, isto é, transformações com liberação e absorção de energia.

A) Relacione esses conceitos com uma reação química de combustão.

B) A $1^{a}$ lei da termodinâmica nos garante que a energia em um sistema isolado é constante, independente do que aconteça em seu interior. Como você explica que, ao adicionar água a uma porção de $\mathrm{NaOH}_{(s)}$ no interior de uma garrafa térmica perfeita (isolamento térmico perfeito), a temperatura sobe vários graus Celsius? Isso contradiz ou não a $1^{a}$ lei? Por quê?

C) Em termos de estruturas químicas, qual a origem da energia liberada em transformacões como as combustões comuns na presença de oxigênio ou a transformação da glicose em nosso organismo? (Questões respondidas por estudantes do Ensino Médio referentes às transformações químicas e efeitos energéticos).

As questões foram respondidas por dez estudantes do Ensino Médio, no período regular de aula (noturno). Cada estudante foi codificado por um número $(1,2,3 \ldots)$, seguido da letra $\mathrm{A}, \mathrm{B}$ ou $\mathrm{C}$, que se refere ao item da questão respondida. Os dez foram escolhidos de forma aleatória, visto que outros estudantes da mesma turma respondiam questões elaboradas por outros grupos de licenciandos que também cursavam PEQ II e pesquisavam sobre outros conteúdos/assuntos químicos referidos anteriormente.

A partir das respostas dos licenciandos e dos estudantes do Ensino Médio, realizouse a leitura cuidadosa das respostas, o que possibilitou o agrupamento segundo a semelhança de nível conceitual já atingido e esperado para o Ensino Médio, conforme entendimentos produzidos pelos licenciandos pesquisadores em seus estudos. No agrupamento das respostas, o olhar voltou-se mais aos conceitos relativos a: reações exotérmicas e endotérmicas; interações em nível atômico-molecular no que se refere ao rompimento e formação de novas ligações químicas; interconversões de energia potencial e cinética em sistemas isolados. Isso permitiu a construção do que o grupo de licenciandos denominou de categorias de análise, não sem o apoio de referenciais teóricos buscados em artigos, livros didáticos do Ensino Médio e Superior, já estudados em outros componentes curriculares do curso ou no próprio componente PEQ II.

O resultado de todo o trabalho realizado pelo grupo de licenciandos pesquisadores foi apresentado em relatório de aproximadamente quarenta páginas. O grupo apresentou, também, um resumo expandido nos moldes exigidos para os trabalhos submetidos à comissão científica da 30ª Reunião Anual da Sociedade Brasileira de Química (RASBQ). Foi preparada, ainda, uma síntese da pesquisa com vistas a ser apresentada aos outros licenciandos que cursavam a PEQ II e aos estudantes da escola que responderam às questões formuladas. Considera-se que a divulgação de resultados de pesquisa é uma etapa essencial da pesquisa e, neste caso, destinava-se a contribuir com a reflexão sobre a melhoria da educação química na escola e na universidade. Posteriormente ao componente curricular, o trabalho desenvolvido pelos licenciandos foi escrito nos moldes exigidos pelo XIV ENEQ, sendo aprovado e apresentado no referido evento.

A seguir, são apresentados resultados da pesquisa realizada pelo grupo de licenciandos ainda durante o desenvolvimento do componente curricular PEQ II, já com acréscimos decorrentes da apresentação de trabalho na RASBQ e no ENEQ. Seguem, depois, considerações sobre a pesquisa desenvolvida e relatada pelos acadêmicos, refletindo sobre potencialidades e sentidos para esse tipo de atividade curricular na formação de professores. 


\section{Resultados e discussões}

Os resultados da pesquisa desenvolvida pelos licenciandos em PEQ II são apresentados em três itens: o primeiro refere-se à análise dos livros didáticos; o segundo, à análise das respostas dos licenciandos; o terceiro, à análise das respostas dos estudantes do Ensino Médio.

\section{Livros didáticos de química do Ensino Médio e do Ensino Superior}

Os livros didáticos foram analisados apenas no que concerne aos conteúdos e conceitos ligados a transformações químicas e efeitos térmicos. Esse assunto é tratado, geralmente, nos capítulos que dizem respeito à termoquímica ou termodinâmica química. A análise se restringiu a esses capítulos.

O LD1 aborda, com mais detalhes, os conceitos de reação exotérmica e endotérmica. Para reação exotérmica, os autores propõem pensar na reação de queima do hidrogênio; para reação endotérmica, a decomposição do carbonato de cálcio e a obtenção de gás hidrogênio e gás oxigênio a partir da água. Os conceitos são trabalhados sem se proporem reflexões que possam relacionar os fenômenos com os modelos atômico-moleculares, e nem há preocupação, por exemplo, em inter-relacionar conceitos importantes sobre interconversões de formas de energia envolvidas nas transformações. Essa forma de apresentação dos conteúdos em livros didáticos é muito comum e, geralmente, leva à memorização mecânica de conceitos, com pouca significação conceitual. Assim, resta apenas substituir uma expressão como "energia liberada" por " $\Delta \mathrm{H}<0$ " ou "transformação exotérmica", como aprendizagem escolar. O livro não contempla conceitos relacionados à energia cinética e energia potencial e nem são discutidas rupturas e formações de ligações nas transformações envolvidas para explicar, por exemplo: a variação da energia potencial e cinética do sistema, a conservação da energia total e a variação de temperatura em sistemas isolados.

No LD2, percebe-se maior preocupação com a classificação e a conceitualização de reações exotérmicas e endotérmicas. Propõe a seguinte reflexão: "por que as reações liberam ou absorvem calor?". Introduz o conceito de energia interna, afirmando que qualquer substância possui certa quantidade de energia armazenada em seu interior, principalmente na forma de energia de ligação entre seus átomos; explica a liberação e absorção pela diferença entre a energia interna dos reagentes (energia inicial) e a energia interna dos produtos (energia final). A partir disso, introduz os termos reação exotérmica e endotérmica. Trata, a seguir, do princípio da conservação da energia, explicando que a energia pode ser transformada, e que "a quantidade total de energia permanece sempre constante". O LD2 não utiliza os conceitos de energia potencial e cinética, o que poderia facilitar o entendimento da variação de temperatura de transformações químicas em sistemas isolados. Não há preocupação maior em contextualizar os conceitos introduzidos com fenômenos da vivência dos alunos e nem em relacionar as transformações químicas com o que ocorre em nível atômico-molecular, como a ruptura e formação de novas ligações químicas.

No LD3, os conceitos são trabalhados de forma contextualizada sobre as transformações químicas, possibilitando entendimentos quanto à absorção de energia necessária para romper ligações dos reagentes e à liberação de energia quando são formadas novas ligações, relacionando isso com o rearranjo de átomos. Os autores do livro expressam apenas o signifi- 
A pesquisa educacional como atividade curricular ...

cado conceitual (definição) de energia cinética e potencial, o que pouco contribui para que os estudantes consigam interpretar situações vivenciais de efeitos energéticos relacionados às conversões de energia cinética e potencial em sistemas isolados em que ocorram processos de transformação química.

No LD4, apresentam-se os conceitos de termoquímica, de energia interna, reações exotérmicas e endotérmicas, utilizando-se equações genéricas de transformações como: "A + B $\rightarrow$ C + D + Calor" e "A + B + Calor $\rightarrow$ C + D". É enunciada a lei da conservação da energia e são feitas algumas relações com o valor de entalpia dos reagentes e produtos e variação de entalpia com liberação e absorção de calor. Os conceitos são apresentados de forma descontextualizada, bem como os exemplos dados não se referem à realidade vivida ou conhecida dos estudantes; não há referência às estruturas atômico-moleculares, para explicar a liberação e absorção de energia, nem à energia cinética e potencial.

No LD5, abordam-se os conceitos de energia cinética e energia potencial, absorção e liberação de energia. Apresentam-se exemplos de situações do cotidiano dos estudantes, como: a conversão de energia potencial em cinética, com uso de analogia mecânica de uma represa de água, ou a mudança de energia cinética de um sistema gasoso mediante injeção de calor, que aumenta a energia interna e cinética das moléculas. Há pouca preocupação com o que acontece em nível atômico-molecular, como o rompimento de ligações entre átomos em uma molécula e a formação de novas ligações. O modelo também não é relacionado à conservação da energia total e à interconversão energia cinética/potencial em sistemas isolados, o que é essencial, em nosso entendimento, para que se compreendam as variações de temperatura e de entalpia em sistemas isolados em que ocorrem transformações químicas.

Os livros da universidade seguem uma apresentação de conteúdos de forma semelhante a muitos livros do Ensino Médio, porém mais ênfase é dada às interconversões de energia em transformações químicas e ao princípio da conservação da energia.

Energia Cinética é a energia que um corpo possui devido ao seu movimento [...]. Energia Potencial é a energia que um corpo possui em função de sua posição [...]. Energia Total de uma partícula é a soma das suas energias cinética e potencial. [...] Uma característica muito importante da energia total é que, se não existem influências externas, ela é constante. A energia cinética e a energia potencial podem converter-se uma na outra, mas sua soma é constante. (ATKINS; JONES, 2001, p. 40-42)

Em geral, os livros da universidade apresentam os significados dos conceitos em forma de definições, tendo pouca preocupação com a sua significação em contextos mais amplos.

A análise de livros didáticos do Ensino Médio e da universidade evidencia que a ênfase é dada nos conceitos de reações exotérmicas (ou liberação de energia) e nas reações endotérmicas (ou absorção de energia). De uma forma ou outra, os fenômenos energéticos são relacionados à quebra de ligações entre átomos e formação de novas ligações e, mais raramente, a interconversões energia potencial e cinética.

Como os livros didáticos costumam ser roteiros básicos das aulas, espera-se que esse conjunto de conceitos, e não outros, "apareça" nas respostas escritas pelos estudantes. 


\section{Compreensões dos licenciandos}

De forma geral, os acadêmicos não responderam à questão de modo a abranger todos os níveis de compreensões possíveis, isto é, não utilizaram todos os conceitos que poderiam estar envolvidos nas explicações sobre as transformações químicas e seus efeitos energéticos. O uso de conceitos e o nível de significação atingido permitem analisar a possível compreensão que os estudantes expressaram sobre o fenômeno referido na questão anteriormente apresentada. A partir de leituras, as respostas foram agrupadas segundo a semelhança, permitindo a construção de quatro categorias de análise, conforme o Quadro 1.

Quadro 1. Categorização do nível de resposta dos licenciandos.

\begin{tabular}{|c|c|}
\hline Categorias de análise & Respostas dos licenciandos \\
\hline 1) Uso "bom" de conceitos científicos & 7I, 11I, 3III, 4III, 6III, 7III. \\
\hline 2) Ideias "confusas" sobre conceitos científicos & 9I, 14I, 18I, 19I, 10II, 2III, 11III. \\
\hline 3) Uso "contraditório" dos conceitos científicos & 2I, 3I, 5I, 6I, 8I, 12I, 20I, 1II, 2II, 3II, 4II, 5II, 6II, 8II, 9II, 11II, 12II, 12III. \\
\hline 4) Uso "insuficiente" de conceitos científicos & 1I, 4I, 10I, 13I, 15I, 16I, 17I, 21I, 7II, 1III, 9III, 8III, 10III, 13III. \\
\hline
\end{tabular}

Nota: Quanto à categorização das respostas dos licenciandos, o quadro permanece original à classificação dada pelo grupo de licenciandos que executou a pesquisa no âmbito do componente curricular PEQ II.

Fonte: Relatório elaborado, em PEQ II, pelos autores deste trabalho.

$\mathrm{Na}$ categoria 1, as respostas estão dentro do esperado para uma aprendizagem inicial dos conceitos centrais da termoquímica. A necessidade de uso dos conceitos para explicar alguma situação, conforme entende Vigotski (2001), indica que houve pelo menos um nível inicial de significação conceitual. Isso permitiu agrupar respostas dentro da categoria 1 , ou uso "bom" de conceitos científicos relacionados às reações que envolvem a absorção (endotérmica) e liberação de energia (exotérmico), a quebra e a formação de novas ligações, apesar de não serem considerados os conceitos de energia potencial e cinética:

Para formação ou quebra de ligações, sempre há energia envolvida, absorção ou liberação da mesma. Quando uma ligação é formada, bá energia liberada, e quando há quebra existe absorção de energia. No caso de uma combustão uma nova ligação é formada (depois de uma dissociação/quebra de ligação) liberando grande quantidade de energia. (3III)

A energia liberada nas reações químicas vem das ligações que, de acordo com o tipo, liberam mais ou menos energia. Essa energia depende do tamanho da molécula, da ionização, da eletronegatividade. (6III)

Sempre que ocorre formação de composto ocorre liberação de energia. A reação de uma determinada substância como o oxigênio presente no ar resulta na formação de $\mathrm{CO}_{2}, \mathrm{H}_{2} \mathrm{O}$ e energia. (7III) 
A pesquisa educacional como atividade curricular ...

A exemplo de 3III, outros estudantes fizeram uso "bom" de conceitos científicos, tendo atingido algum nível conceitual, compatível com o que é apresentado nos LDS, como, por exemplo, acerca da origem do fenômeno energético: absorção de energia na ruptura de ligações e liberação de energia na sua formação. Outros (6III e 7III) demonstraram ter boa interpretação, utilizando bem os conceitos. A expectativa, porém, era que explicassem a origem da energia com base nas interações atômico-moleculares, genericamente entendidas como rompimento e formação de ligações. Apesar de terem atingido a categoria 1 de resposta, isto é, a de maior nível de significação conceitual, as explicações dos acadêmicos ainda são limitadas no que diz respeito à interconversão energia potencial e cinética para fenômenos descritos, em que varia a temperatura em sistemas isolados.

$\mathrm{Na}$ categoria 2, foram agrupadas respostas com significados "confusos" acerca dos conceitos utilizados para responder a questão:

Vêm dos átomos envolvidos na transformação esses átomos liberam energia para serem transformados. (14I)

Vem do material usado, e do modo que é usado. Depois da mistura dos materiais, então teremos a combustão dos produtos. Alguns precisam ser excitados para entrar no processo de combustão, a base de aquecimento, etc. (2III)

Combustivel + comburente. A energia liberada provém da ligação que ocorre entre o combustivel e o comburente e forma água no estado de vapor e "derivados" de carbono. Lembrando que este é um processo exotérmico, todas as combustões se comportam dessa forma, com liberação de energia, pois as moléculas do produto possuem menor energia que as dos reagentes. (19I)

Os termos científicos esperados muitas vezes não são utilizados ou são utilizados incorretamente pelos acadêmicos, havendo confusão por parte dos mesmos, como evidenciam, de imediato, as respostas apresentadas acima. A não-necessidade de utilização da palavra/ conceito, com base em Vigotski (2001), para produzir algum pensamento sobre uma situação dada, mostra que o primeiro nível de significação conceitual ainda não aconteceu.

$\mathrm{Na}$ categoria 3, houve uso "contraditório" dos conceitos científicos nas explicações sobre a absorção de energia durante a quebra de ligações nos reagentes, e a liberação de energia resultante da formação de novas estruturas moleculares nos produtos. As explicações consideradas mais representativas da amostra foram:

A energia liberada é originada quando uma ligação química é rompida e liberará energia para o meio. Neste caso a reação é denominada exotérmica. Nesse caso ligações são rompidas e novas são estabelecidas. (6II)

O efeito vem da quebra entre as ligações intramoleculares das moléculas, causa uma enorme liberação de energia, para então posteriormente ocorrer novas interações entre os átomos. Formando consequentemente novas substâncias. (4II) 
Sangiogo, F. A. et al.

Esta energia liberada nesse tipo de reações químicas vem da quebra das moléculas em transformação; isto se deve a capacidade de romper as forças moleculares e intermoleculares. (1II)

Vem da agitação dos átomos, que ao se agitar liberam certa quantidade de energia, e quando bá rompimento de ligações químicas há liberação de energia. (6I)

Nessa categoria percebe-se que os licenciandos não têm conhecimentos químicos suficientes e minimamente significados de modo a permitirem interpretação de situações vivenciais. Isso ficou evidenciado pelo emprego incorreto de alguns dos conceitos químicos, como, por exemplo, de que a energia liberada é resultante da quebra de ligaçoes. Chama atenção, ainda, a forma confusa de escrita de alguns estudantes, mostrando pensamentos com pouca lógica.

$\mathrm{Na}$ categoria 4, foram agrupadas respostas em que os estudantes não conseguiram responder a questão, por utilizarem de forma insuficiente os conceitos de nível atômico-molecular da química. Os átomos, por exemplo, são considerados entidades existentes e sem relação com alguma substância, como dá a entender o estudante 10I. Outros falam qualquer assunto relacionado, próprio do senso comum, sem fazer relação com o conteúdo sobre o qual foram solicitados a responder, como 8III:

A energia liberada vem dos átomos que se unem fazendo com que aconteçam as transformações químicas. (10I)

Muitas transformações com efeitos energéticos ocorrem no nosso dia-a-dia, como a combustão. Para que ocorra a combustão é necessário que haja presença de oxigênio. Se acendermos 2 velas de $4 \mathrm{~cm}$ cada e deixarmos uma na presença de oxigênio, e a outra cobrirmos com um copo a chama acaba, cessando a combustão pela falta de oxigênio. (8III)

Pode-se afirmar que, de forma geral, os acadêmicos tiveram dificuldades em responder com boa compreensão conceitual a questão proposta. Pouco inter-relacionam as expressões: reações exotérmicas e endotérmicas, quebra e formação de ligações, interconversão energia potencial/cinética, conservação da energia em sistemas isolados, e variação de temperatura nesses sistemas - conceitos considerados, pelo grupo de licenciandos, como os esperados e necessários para uma resposta mais completa à questão realizada.

\section{Compreensões dos estudantes do Ensino Médio}

A partir de leituras cuidadosas das respostas dos estudantes do Ensino Médio quanto ao seu nível conceitual atingido, foram agrupadas respostas no que se denominou de categorias de análise, conforme mostra o Quadro 2. 
A pesquisa educacional como atividade curricular ...

Quadro 2. Agrupamento, nas categorias, por nível de resposta dos estudantes do Ensino Médio.

\begin{tabular}{|l|l|}
\hline \multicolumn{1}{|c|}{ Categoria de análise } & \multicolumn{1}{|c|}{ Respostas dos estudantes do Ensino Médio } \\
\hline 1) Responderam segundo algum nível conceitual esperado & 1A, 4A, 6A, 7A, 8A, 9A, 10A. \\
\hline $\begin{array}{l}\text { 2) Responderam de forma "confusa", não mostraram ter } \\
\text { conhecimento sobre o conteúdo escolar }\end{array}$ & $3 \mathrm{~A}, 5 \mathrm{~A}, 1 \mathrm{~B}, 3 \mathrm{~B}, 2 \mathrm{C}, 3 \mathrm{C}, 4 \mathrm{C}, 7 \mathrm{C}, 10 \mathrm{C}$. \\
\hline 3) Respostas contrárias aos conceitos científicos & 2A, 2B, 4B, 7B, 8B, 9B, 10B, 1C. \\
\hline 4) Não tentaram responder & $5 \mathrm{~B}, 6 \mathrm{~B}, 5 \mathrm{C}, 6 \mathrm{C}, 8 \mathrm{C}, 9 \mathrm{C}$. \\
\hline
\end{tabular}

Nota: Quanto à categorização das respostas dos estudantes do Ensino Médio referentes às perguntas elaboradas na fase III da pesquisa, o quadro permanece original à classificação dada pelo grupo de licenciandos que executou a pesquisa no âmbito do componente curricular PEQ II. Fonte: Relatório elaborado, em PEQ II, pelos autores deste trabalho.

Na categoria 1, os estudantes se expressaram sobre a diferença das reações exotérmicas (que liberam energia) e endotérmicas (que absorvem energia). Esse nível de resposta foi representativo apenas para a questão "A" e não se estendeu muito além de exemplificações. Evidencia um pensamento ainda por complexos, não propriamente categorial, conforme Vigotski (2001) argumenta em estudo sobre a formação dos conceitos científicos. Esse pensamento se caracteriza por manter traços do concreto, isto é, com pouca capacidade de abstração:

Exotérmica: combustão de álcool, formação de nuvem de chuva, a partir do vapor d'água do ar. Endotérmica: sublimação da naftalina, degelo do freezer. (10A)

$\mathrm{Na}$ categoria 2, os estudantes não responderam com uso de palavras/conceitos relacionados ao conteúdo escolar sobre termoquímica. Praticamente não utilizaram conceitos escolares estudados ou, então, mostraram significados confusos:

Exotérmica - liberação de energia com a queima do papel. Endotérmica - absorção de energia da queima de combustivel. (5A)

Não, pois aumenta a temperatura. (1B)

Não, porque quando a variação de energia em um sistema isolado é constante, sua temperatura também será constante, pois existe movimentação entre as moléculas.

Através da absorção de oxigênio e da liberação de gás carbônico. (7C)

A origem das combustões ocorre na absorção de oxigênio e depois a liberação do gás carbônico, ou seja, libera energia. (3C)

Na categoria 3, os significados dados às palavras que representam conceitos científicos no contexto escolar parecem caminhar na contramão dos significados que deveriam ter: 
Sangiogo, F. A. et al.

$\mathrm{Zn}+\mathrm{H}_{2} \mathrm{SO}_{4} \rightarrow \mathrm{ZnSO}_{4}+\mathrm{H}_{2}$ Exotérmica. (2A)

Porque a concentração de $\mathrm{NaOH}$ é muito alta quando ocorre a reação. (7B)

Sim, pois a água fica concentrada na térmica, e o que faz com que ela se aqueca cada vez mais e o isolante dela, ela não está em constante contato com o meio externo, por isso demora mais para mudar a temperatura. (8B)

A energia vem da quebra das moléculas, ai transformando o alimento em energia em nosso organismo. (1C)

1C mostrou algum conhecimento frente à energia liberada e levou em consideração a estrutura das moléculas.

Com base nos resultados da pesquisa desenvolvida, pode-se concluir: a maioria dos estudantes do curso de Química-Licenciatura e do Ensino Médio que respondeu as questões apresentadas acerca da origem dos efeitos energéticos em reações químicas conhecidas encontra dificuldades para produzir uma resposta que possa ser considerada satisfatória em termos do que ocorre em nível atômico-molecular.

Constatou-se também que as expressões "reação exotérmica" e "reação endotérmica" são utilizadas pelos licenciandos para se referirem a transformações químicas que geram efeitos energéticos conhecidos, mas se confundem quando são solicitados a explicitar a origem da energia nessas reações. Neste caso, fazem pouca menção às estruturas atômico-moleculares e às interconversões de energia que ocorrem, como, por exemplo, a variação de temperatura em sistemas isolados. Estudantes do Ensino Médio conseguem indicar alguns exemplos de reações químicas classificáveis como exotérmicas e endotérmicas, e poucos associam isso às mudanças nos arranjos atômicos em moléculas envolvidas nas transformações. Ambos os grupos de sujeitos praticamente não mencionam a conservação da energia em sistemas isolados em que ocorrem transformações e, muito menos, tentam atribuir a origem da variação na temperatura, que se observa nessas reações, à interconversão energia potencial e cinética, ou que a variação de temperatura esteja ligada à energia cinética média das partículas que compõem o sistema.

Livros didáticos analisados apresentam nível de problematização e discussão muito semelhante àquele apresentado pelas respostas mais próximas das explicações científico-escolares constatadas: muita ênfase é dada a cálculos de energia (valores de $\Delta \mathrm{H}$ ) em dada equação química, num exercício de somar e subtrair calores de formação. Pouca ênfase é dada à significação conceitual e à relação entre conceitos. Isso pode explicar, em parte, os pensamentos restritos que os estudantes produzem sobre as transformações químicas apenas em termos de controle de quantidades estequiométricas, sem levar em consideração os efeitos decorrentes dos rearranjos atômicos nas transformações químicas. 
A pesquisa educacional como atividade curricular ...

\title{
Considerações sobre a pesquisa educacional na formação docente
}

Os resultados de pesquisa, produzidos na forma de relatório científico, resumo de pesquisa nos moldes da $30^{a}$ RASBQ e trabalho completo para o XIV ENEQ, denotam bom desenvolvimento dos licenciandos ao se propor a pesquisa educacional como atividade curricular. Entende-se que isso seja possível quando as atividades de iniciação à pesquisa educacional são distribuídas ao longo dos semestres do curso, em espaços privilegiados, como em PEQ II. Deve haver, por exemplo, flexibilidade no fechamento do componente dentro das normas institucionais, como postergar a entrega dos relatórios após os períodos de recesso semestrais, executando etapas da pesquisa ainda um ou dois meses quando os acadêmicos não costumam ter atividades curriculares normais. Isso acontece, geralmente, em julho, após o término do primeiro semestre, ou em dezembro e janeiro, após o término do segundo semestre.

A experiência dos docentes orientadores nesse tipo de atividades também é fundamental e todos testemunham o empenho dos licenciandos nessa atividade. Ela permite uma apropriação mais qualificada, inclusive, do conhecimento específico da química, como o referente às transformações químicas e seus efeitos energéticos, analisado neste artigo. As atividades desenvolvidas aproximam-se bastante daquelas da IC, como: a elaboração do projeto de pesquisa, produção e análise de dados, no caso, próprios da pesquisa educacional, elaboração de relatórios e outros. No que se refere ao desenvolvimento profissional da docência, podemse citar: contato com professores e alunos de escolas, identificação e análise de livros didáticos, exercício da escrita com base em argumentos, capacidade de elaboração de perguntas adequadas para avaliações de resultados do processo de ensino e aprendizagem, entre outros.

Compreende-se, há mais tempo, que o desenvolvimento dessas atividades de pesquisa educacional pode contribuir na formação de professores pesquisadores, como aponta Maldaner (2003) e Wenzel (2007), formando profissionais com maior capacidade para analisar situações de ensino e de aprendizagem com que irão se deparar no contexto escolar.

O trabalho de dissertação de Wenzel (2007), que analisou os componentes de Pesquisa em Ensino de Ciências I e II na formação dos licenciandos de Química da Unijuí, permitiu concluir que a vivência do fazer pesquisa pelo licenciando permitirá que o mesmo esteja

\begin{abstract}
preparado para se tornar um professor pesquisador em sua prática, visto que teve uma iniciação do fazer pesquisa e já foi percebendo a força e a importância dessa prática para construir conhecimentos, criar abertura para mudanças, para continuar produzindo e divulgando resultados de pesquisas e reflexões sobre as práticas, buscando e produzindo avanços sistemáticos em sua formação intelectual e profissional. (WENZEL, 2007, p. 127)
\end{abstract}

Em PEQ II, os licenciandos, além de aprenderem a fazer pesquisa, podem refletir e aprender mais sobre conceitos com que irão atuar como futuros professores de Química, capacitando-os a analisar possíveis aprendizados por parte dos estudantes do Ensino Médio. Ou seja, com a pesquisa, os licenciandos tiveram de estudar mais para melhor entenderem o conteúdo sobre transformações químicas e para poderem ordenar as respostas dos estudantes em distintos agrupamentos e categorias de análise. Isto, é claro, dentro dos limites teóricos e 
conceituais que possuem. A pesquisa educacional com atividade curricular assemelha-se à pesquisa de IC desenvolvida por alguns estudantes da graduação. Inclusive, possibilita que todos os licenciandos sejam motivados e tenham oportunidade de escrever e participar de eventos da área de ensino e educação em ciências.

Devem ser considerados, também, os limites nesse tipo de atividade curricular, principalmente na análise de suas produções. Entre esses limites, sempre com base na reflexão sobre o trabalho desenvolvido pelo grupo foco deste artigo, apontam-se: nível de significação conceitual, embora ampliado pelo estudo específico para a realização da pesquisa, em relação aos outros licenciandos que responderam a questão referente às transformações químicas, ainda merece "reparos" ou vigilância epistemológica sobre o que o grupo conseguiu produzir; dificuldade de produção de categorias mais consistentes e análise possível a partir da riqueza de dados produzidos; dificuldades de orientação por parte do professor do componente curricular, que precisa atender, simultaneamente, vários grupos de pesquisa e com questões diferentes; a divisão de tarefas do próprio grupo de pesquisa interfere nas análises desenvolvidas por um ou outro licenciando, prejudicando a elaboração de um texto mais coerente quanto à análise dos materiais empíricos. Também é importante considerar que estudantes de cursos noturnos têm mais dificuldades para os encontros, pois trabalham no período diurno. Tudo isso não pode ser desconsiderado na avaliação dos resultados dessa experiência de formação pela pesquisa nas licenciaturas.

Deve-se ressaltar a compreensão que os licenciandos/pesquisadores produzem sobre a realidade da aprendizagem escolar ou a tomada de consciência sobre a incipiente significação conceitual dos estudantes do Ensino Médio ou Superior sobre situações vivenciais, como a combustão. Ao mesmo tempo, a partir do campo teórico, passam a entender que a utilização de conceitos científico-escolares para explicar uma situação real é muito mais difícil do que repetir as definições prontas dadas aos conceitos ou aplicar algoritmos de solução de exercícios numéricos. Isso denota a importância de se repensar a organização do ensino escolar, seja na escola básica ou Ensino Superior, bem como de se refletir sobre as expectativas para a aprendizagem escolar e universitária. As avaliações externas, como o Enem (Exame Nacional do Ensino Médio) e o Enade (Exame Nacional de Desempenho de estudantes do Ensino Superior), sempre apontam esses níveis ainda elementares de significação do conhecimento escolar e universitário, quando se trata de analisar situações práticas com base nesses conhecimentos.

Resultados da pesquisa remetem para considerações defendidas na introdução deste trabalho, quais sejam: a necessidade de se desenvolverem processos de ensino que considerem articulações entre conhecimentos cotidianos e científicos, processos de ensino que necessitam da apropriação e ressignificação de conceitos específicos da ciência, tal como propõe Vigotski (2001).

A pesquisa desenvolvida pelos licenciandos permite que os mesmos avancem, também, quanto ao entendimento equivocado, mas corrente, de que "tudo vai ser aprendido de uma só vez, desde que o professor mostre o conteúdo" (GALIAZZI, 2003, p. 197). Eles evidenciaram, em sua pesquisa, o incipiente uso de conceitos de natureza científica por parte dos estudantes da universidade e do Ensino Médio quando são solicitados a interpretar situações que envolvem efeitos energéticos. Espera-se que isso reflita em futuras práticas docentes, de modo que os mesmos considerem a apropriação e significação de conceitos ou conheci- 
A pesquisa educacional como atividade curricular ...

mentos escolares como um processo complexo e permanente.

De forma geral, depreende-se que a análise realizada pelos licenciandos/ pesquisadores carece de articulações com referenciais teóricos usados no relatório e no trabalho apresentado no ENEQ, e os argumentos que orientaram os níveis conceituais expressos pelos mesmos devem evoluir para novos estágios. Deve-se considerar isso como algo normal, pois eles estão realizando os primeiros passos, e, mesmo assim, há ganhos consideráveis em seu desenvolvimento intelectual, conforme evidenciado e argumentado neste artigo.

Considerando-se o exposto, evidencia-se que os licenciandos, dentro de suas limitações, conseguem realizar pesquisa como atividade curricular, no curso de licenciatura. Com base nisso, defende-se que pesquisas - a exemplo da apresentada neste trabalho - permitem iniciar a formação de professores pesquisadores, que sejam mais capazes de tomar consciência dos aprendizados decorrentes das suas aulas, permitindo, assim, romper com modelos tradicionais de ensino que se baseiam na racionalidade técnica. Compreende-se que tais profissionais podem possibilitar melhores processos de apropriação e significação de conceitos escolares (VIGOTSKI, 2001), de modo que conhecimentos estudados possam ser socialmente relevantes para a vida dos estudantes, a exemplo das interpretações em nível atômico-molecular de situações vivenciais.

\section{Referências}

ATKINS, P. Físico-química: fundamentos. 3. ed. Rio de Janeiro: LTC, 2001.

ATKINS, P.; JONES, L. Princípios de química. Porto Alegre: Bookmann, 2001.

BACHELARD, G. A formação do espírito científico: contribuição para uma psicanálise do conhecimento. Rio de Janeiro: Contraponto, 1996.

BARROS, H. L. C. Processos endotérmicos e exotérmicos: uma visão atômico-molecular. Química Nova na Escola, São Paulo, v. 31, n. 4, p. 241-245, 2009.

BRASIL. Ministério da Educação. Secretaria de Educação Básica. Orientações curriculares para o Ensino Médio. Brasília: MEC, 2006. v. 2.

CARVALHO, G. C.; SOUZA, C. L. Química de olho no mundo do trabalho: Ensino Médio. São Paulo: Scipione, [20-].

EBING, D. Química geral. 5. ed. Rio de Janeiro: LTC, 1998. v. 1.

FELTRE, R. Fundamentos da química: volume único. 3. ed. São Paulo: Moderna, 2001.

FONSECA, M. R. Química: físico-químico. São Paulo: FTD, 1992.

GALIAZZI, M. C. Educar pela pesquisa: ambiente de formação de professores de ciências. Ijuí: Ed. Unijuí, 2003.

LOPES, A. R. Conhecimento escolar: inter-relações com conhecimentos científicos e cotidianos. Contexto e Educação, Ijuí, v. 11, n. 45, p. 40-59, 1997. 
Sangiogo, F. A. et al.

LÜDKE, M; ANDRÉ, M. Abordagens qualitativas de pesquisa: pesquisas qualitativas. São Paulo: EPU, 1986.

MALDANER, O. A. A formação inicial e continuada de professor de química: professores/pesquisadores. 2. ed. Ijuí: Unijuí, 2003.

MALDANER, O. A.; ZANON, L. Situação de estudo: uma organização do ensino que extrapola a formação disciplinar em ciências. Espaços da Escola, Ijuí, v. 11, n. 41, p. 45-60, 2001.

MASTERTON, W. L.; SLOWINSKI, E. J.; STANITSKI, C. L. Princípios de química. 6. ed. Rio de Janeiro: LTC, 1990.

MORIN, E. Os sete saberes necessários à educação do futuro. 11. ed. São Paulo: Cortez, 2006.

ROSA, M. I.; SCHNETZLER, R. P. Sobre a importância do conceito transformação química no processo de aquisição do conhecimento químico. Química Nova na Escola, São Paulo, v. 8, n. 2, p. 31-35, 1998.

SANGIOGO, F. A. et al. Transformações químicas e seus efeitos energéticos: compreensões de estudantes da licenciatura de química e do Ensino Médio. In: ENCONTRO NACIONAL DE ENSINO DE QUÍMICA, 14., 2008, Curitiba. Anais... Curitiba: UFPR, 2008. 1 cd-rom

SANTOS, W. L.; MÓL, G. S. (Org.). Química e sociedade: Ensino Médio volume único. São Paulo: Nova Geração, 2005. (PEQUIS - Projeto de ensino de química e sociedade).

SANTOS, W. L.; SCHNETZLER, R. P. Educação em química: compromisso com a cidadania. Ijuí: Unijuí, 1997.

SCHÖN, D. The reflective practitioner. New York: Basic Books, 1983.

SOUZA, V. C. A. Os desafios da energia no contexto da termoquímica: modelando uma nova ideia para aquecer o ensino de química. 2007. 205f. Dissertação (Mestrado em Educação) - Faculdade de Educação, Universidade Federal de Minas Gerais, Belo Horizonte, 2007.

SOUZA SANTOS, B. Um discurso sobre as ciências. São Paulo: Cortez, 2003.

VIGOTSKI, L. S. A construção do pensamento e da linguagem. São Paulo: Martins Fontes, 2001.

WENZEL, J. S. A prática do ensinar e do aprender a fazer pesquisa em componentes curriculares de um curso de licenciatura em química. 2007. 147f. Dissertação (Mestrado em Educação em Ciências) - UNIJUI, Ijuí, 2007.

YOUNG, M. Para que servem as escolas? Educação \& Sociedade, Campinas, v. 28, n. 101, p. 1287-1302, 2007. Disponível em: <http://www.scielo.br/pdf/es/v28n101/ a0228101.pdf>. Acesso em: 30 out. 2008.

Artigo recebido em 30/06/2010. Aceito em 05/12/2010. 